\title{
Morality and Social Identity ๖
}

\author{
Naomi Ellemers
}

The Oxford Handbook of the Human Essence

Edited by Martijn van Zomeren and John F. Dovidio

Print Publication Date: Jan 2018 Subject: Psychology, Social Psychology

Online Publication Date: Nov 2017 DOI: 10.1093/oxfordhb/9780190247577.013.5

\section{Abstract and Keywords}

Moral norms and values are key features of human essence, that provide the standards against which behavior is evaluated. Some moral norms and values are universally endorsed (e.g., "do no harm"), others can be more specific (e.g., "eat no meat"). Professional, cultural or religious groups and communities often define their own unique system of moral norms that true group members are expected to adhere to. These are used to identify 'proper' group members, regulate the behavior of individuals, and sanction those who transgress them. This is functional to the extent that such guidelines help provide groups and their members with a unique and distinct social identity. Yet they can also constitute a source of social tension and intergroup conflict. This hallmark feature of human morality represents an important challenge to contemporary societies.

Keywords: intergroup conflict, moral behavior, morality, moral norms, moral values, social identity, human essence, human behavior, social groups, social tension

\section{Morality and Social Identity}

Moral norms and values distinguish between "right" and "wrong," and indicate which behaviors are considered socially acceptable or unacceptable. However, political, religious, or ethnic groups differ in what they consider moral or immoral behavior, how they expect their members to behave, and whom they consider to be "real" humans. Because moral guidelines and judgments help provide groups and their members with a unique and distinct social identity, these constitute a key feature of human essence.

This chapter first elucidates the relevance of morality to human essence, by comparing human morality to animal morality. Then it explains the social functions of moral group norms and shared moral values in guiding the behavior of individuals. The chapter concludes by considering the positive as well as the negative impact these features of the human essence may have in modern societies. 


\section{Morality as a Mark of Humanity}

This first section starts by considering which behavioral displays among animals are seen as indicating morality. This helps specify the communicative and symbolic properties of moral judgments and moral concerns, which make human morality fundamentally different from moral behavior in animals.

\section{Animal Morality}

Biological analyses of moral behavior often take an evolutionary perspective, as (p. 148) they consider whether and how human morality can be seen to originate in animal behavior. Nuancing lay conceptions that evolution favors survival of the fittest, this approach explains why selfish behavior is not always adaptive, especially in communities of individuals living together. Individuals who depend on each other for physical safety or access to food may find it necessary to exchange goods or favors with each other. In such contexts, mutual helping behaviors can benefit individual as well as community survival. Further, animal communities usually consist of individuals with close kinship relations (between siblings, or between parents and offspring), so that community wellbeing also enhances individual genetic survival in the gene pool.

Examinations of morality from this perspective tend to focus on the similarities between animal behavior and human behavior (De Waal, 1996). These include displays of empathy (for instance when elephants seem to be affected by the suffering of other individuals), apparent concerns about fairness (for instance in food sharing), or helping others escape danger (for instance among primates). Notably, these forms of other-oriented behavior tend to be observed among specific individuals who directly interact with each other or live together in the same community. The known examples of other-oriented behavior among animals make it difficult to exclude the possibility that this is part of a tit-for-tat system in which individuals depend on each other to achieve what in the end are selfish goals, such as access to food or personal security.

Even if we assume that the perspective and well-being of other individuals-instead of indirect selfishness-is the driving force here, observed examples of "moral behavior" among animals all can be labeled as forms of altruism, empathy or helping, exemplifying very generic other-oriented behaviors. Parallels in human interactions would be seen to indicate "universal morals": a basic awareness that the outcomes and well-being of others have to be taken into account, even when pursuing selfish goals. Obviously, this type of basic awareness is relevant to enable communities of individuals to live in close proximity to each other. However, it is less clear to what extent these behaviors capture the essence of human morality.

\section{Symbolic Implications of Human Behavior}

Human morality is different from animal morality in that it also encompasses more abstract, symbolic implications of specific behaviors that can become dissociated from their 
original survival value. It involves the cultural and social anchoring of specific moral guidelines, for instance in religions. Among humans, behaviors that may once have benefited individual and group survival, over time tend to evolve in culturally meaningful moral guidelines that help distinguish group members from those outside the group, even if they prescribe behaviors that have become physically maladaptive. For instance, the wearing of fur hats protected the Jewish Chassidic community from the cold when they lived in Russia, but no longer has this direct survival value for those who live in Jerusalem. Yet this behavior is maintained and has acquired moral overtones as a mark of identity for "true believers." Hence it has become socially functional.

Similar accounts can explain the persistence of elaborate and no longer obviously functional rules prescribing "right" versus "wrong" ways of food preparation, ritual cleansing, or clothing habits. The historical origin of these moral rules can often be traced to primitive living circumstances, (p. 149) where such strict behavioral guidelines may have prevented food poisoning or spread of disease in the community. Yet even with the original circumstances long gone, these strict behavioral rules persist and are seen as "morally right" and the only acceptable forms of behavior in the communities that endorse them.

This illustrates the social functions of human morality, where behavioral rules and habits that may once have originated to protect individual and group survival, over time have become distinctive a mark of religion, tradition, and group belonging. This so-called twotier analysis (Tomasello \& Vaish, 2013) distinguishes human from animal morality. It also suggests that human morality taps into mechanisms that require very subtle and elaborate communication in the form of spoken or written language. This is needed to transfer specific thoughts and rationalizations that imbue relatively neutral behaviors (e.g., (not) preparing or eating food at a particular time of the day, week, or year) with specific social meanings.

Quite sophisticated forms of communication and indications of self-awareness are also observed in animal species known to be highly intelligent. For instance, bottlenose dolphins use an unique individual signature whistle to broadcast their own identity to others. This whistle is then copied and used by others to capture their attention and address them (Janik, 2013). In captivity, these dolphins can learn to use acoustic labels to indicate the presence versus absence of specific objects. Yet the reliance on highly subtle nuances of meaning and the scope at which this takes place is typically considered to be unique for humans and the special role of language in human communication.

The display of moral behaviors that extend to individuals that have no direct kinship or interdependence relations or do not even know or directly interact with each other also is not generally observed in animals. This too is characteristic of human morality. The symbolic nature of human morality and its role in defining and maintaining relations within and between different groups of individuals in larger and more complex societies adds another layer of meaning. Together, these aspects of morality reflect the human essence that makes it distinct from animal morality. 
Moral behavior of humans thus is more complex and multi-faceted than animal morality, even if it is rooted in similar origins. This makes human moral behavior fundamentally different. Among humans, almost any form of behavior that communicates awareness of specific social rules and invites moral judgment can come to be seen as a mark of morality (or immorality). This includes altruism and helping behavior, but also extends to a variety of behaviors and sometimes very private choices that do not necessarily affect others, relating to physical integrity, spiritual activities, or food consumption. These specific behaviors sometimes only acquire moral implications at a very local level, for instance in a specific religious community. Thus, the essence of human morality is encapsulated in its symbolic function in communicating to ourselves and others who we are and where we belong.

\section{Beyond Altruism}

Addressing the symbolic and communicative functions of moral judgments among humans implies that we need to go beyond behavioral observations of altruism to understand human morality. The next section considers different aspects that characterize human moral behavior by pointing out the limits of equating moral behavior to empathy and fairness, by distinguishing (p. 150) morality from sociability, considering guilt and shame as characteristic "moral emotions," and examining how people define their "circle of care."

\section{Empathy and Fairness}

Philosophers refer to moral principles as indicating what is a "good," "virtuous," "just," "right," or "ethical" way for humans to behave (Haidt \& Kesebir, 2010). Drawing on animal "morality" and evolutionary insights, fairness and empathy with others are considered key moral concerns that can help regulate individual behavior in social communities. At the same time, these guidelines tend to be defined in relatively abstract terms. They admonish people to pursue the greatest good for greatest number, or they consist of variations on the "golden rule": do not treat others the way you would not wanted to be treated yourself. These approaches clarify that it is important for individuals to curb their selfinterest as a way to maintain long-term interdependence relations with others, and facilitate community life.

The common assumption underlying these approaches is that individual exemplars (of animal species as well as humans) may differ in the extent to which they take these moral principles as a guideline for their actions. This is commonly examined by studying individual decision making in moral dilemmas-forcing people to choose the least of two evils in a trade-off-to reveal their moral preferences. The choices individuals make are used to draw conclusions about the importance they attach to equally distributing outcomes between self and others (e.g., to indicate fairness) or how willing they are to sacrifice their own well-being or resources to extend help to the weak (e.g., to infer empathy). In this approach, human moral identity is seen as indicating an individual's overall willingness to 
consider the plight and outcomes of others in making decisions about the pursuit of their own goals. Individuals can then be diagnosed in terms of the extent to which they have developed the general ability and inclination to do this, as a result of their personal character and the way this was shaped by important experiences during childhood. As a result, those who display selfish or unfair behavior are seen as individuals lacking in empathy and altruism.

\section{Morality versus Sociability}

The tendency to consider the willingness to defer selfish goals-and display altruism-as the core feature of human moral behavior can be understood from the parallels that are drawn with animal morality. This has led to approaches and measures in which a general distinction is made between on the one hand the broad range of task-related behaviors that are relevant to personal goal achievement, and on the other hand all manner of social interactive behaviors-indicating how individuals relate to each other. The class of social interactive behaviors contains features that characterize the extent to which individuals seem forthcoming and willing to engage with others (friendliness, warmth) as well as acts that can be seen to indicate their benevolent versus harmful intentions (trustworthiness, reliability). Yet friendliness and reliability do not always go together (see also Fiske \& Rai, 2014). Think of a colleague or acquaintance whose brutally honest judgments on aspects of your character in need of improvement seem reliable and ring true, which make them all the more hurtful.

Accordingly, empirical research has established that-within the cluster of relational behaviors-acts that indicate sociability in interactions with others (p. 151) (friendliness, altruism, helping) are seen as distinct from acts that indicate morality as a behavioral standard defining the ideal self (honesty, sincerity, reliability). These are different and relatively independent judgments that individuals use to diagnose and predict the quality of social interactions. Both are taken into account alongside task-related features indicating competence, as three main pieces of information that help us when forming impressions of other individuals or groups, and jointly determine our self-views. Further, when making this distinction, evidence obtained across a variety of empirical measures and research contexts reveals that people attach more value to information indicating the morality of self and others than to indicators of their sociability, or even to their competence in goal achievement (Ellemers, Pagliaro, \& Barreto, 2013).

Whereas people certainly appreciate displays of friendly, empathic, or altruistic behavior as facilitating social interactions, behaviors that help determine the honesty, reliability, or sincerity of individuals and groups weigh more heavily in the overall impression they form of who these others really are and what they stand for. Compared to information demonstrating one's sociability or competence, moral information can be considered as more revealing of underlying intentions or goal priorities. Accordingly, it has been established as being more attention grabbing, is seen as more diagnostic of someone's "true" self and identity, and is considered more predictive of future behavior. Moral behaviors (e.g., honesty) are more important than sociable (e.g., friendliness) or competent behaviors (e.g., 
displays of intelligence) in determining the impression people form of other individuals and groups (e.g., their colleagues at work), as well as of the views they hold of themselves and the groups they belong to. Moral goals also prove a stronger force than the goal to be competent or sociable in motivating people to behave in line with social norms and ideal self-views. From all this research morality emerges as a central feature that defines the essence of the human beings we are and want to be.

\section{Guilt and Shame}

The heightened importance of behavioral information that can reveal one's morality is also visible in the emotions that are typically raised when people confront their own moral shortcomings: shame and guilt. The self-condemning nature of these emotions can have paradoxical effects (Tangney \& Dearing, 2002). These emotional states can make people feel so bad about themselves-in the domain that is so important for their self-views and their image in the eyes of others-that they are difficult to cope with in a constructive way. The experience of shame and guilt about moral lapses or shortcomings therefore easily tempts people into self-justifying explanations for their behavior, as the consequences of admitting to moral failure are so devastating (Shalvi, Gino, Barkan, \& Ayal, 2015). Thus, paradoxically, attempts to avoid guilt and shame as self-condemning emotions can raise moral disengagement and invite moral justifications for questionable behavior-instead of making people engage in attempts at self-improvement. The primary importance of moral judgments in human interactions makes people less accepting of moral flaws of others, and less open to criticism of moral behavior displayed by the self. At the same time, these defensive and self-justifying responses stand in the way of moral improvement (Giner-Sorolla, 2012).

Notwithstanding the importance humans attach to moral judgments about the (p. 152) behavior of self and others, these judgments are not necessarily contained in the behavior itself. Instead, the moral implications of one's behavior are inferred from the social meaning attached to this behavior, which can be quite symbolic, as in the case of seemingly outdated religious or cultural practices. Judgments of human morality thus rely on complex narratives about underlying motives, as well as justifications about the discrepancy between true intentions (who you are) and overt behavioral displays (what you do). This requires quite sophisticated communication about the interpretation of specific acts, the assignment of social meaning to ambiguous behaviors, and the achievement of social consensus about their acceptability. Such judgments involve a high level of complex reasoning and mutual perspective taking to infer and explain underlying motives of self and others, which are considered typical for humans.

These empirical observations make clear that, among humans, moral behavior and moral judgments do not simply revolve around displays of altruism or fairness. Instead, there is a quite fundamental distinction between morality versus sociability aspects of social interactions and person judgments that determine the way people relate to others around them: Friendly behavior indicates how you choose to engage with others, moral behavior reveals what your true intentions are. In fact, the most effective "con artists" are those 
who use their caring demeanor to exploit others for their own benefit. This also implies that learning about human morality requires more than assessing individual differences in the tendency to display empathy or altruism in affecting the outcomes of others.

\section{Circle of Care}

This brings us to another reason why human morality cannot be fully understood by drawing parallels with displays of empathy and altruism among animals. The likely interaction partners are limited and well-defined in small communities of animals living together. However, this is no longer the case in much larger and complex human societies, where individuals can and do connect to seemingly infinite numbers of others around the world. Digitalized communications, virtual interactions, globalization and large scale migration all press upon us the question of where our circle of care stops (Haslam \& Loughnan, 2014). So when we extend our help to others, or strive for fair distribution of outcomes between ourselves and others, which others do we take into account? Where do we draw the line in engaging with the plight of other human beings, and how much of our own goals and needs are we willing to give up for them? Knowing that someone is an empathic person or generally willing to behave altruistically does not help us answer these questions.

Human morality thus is context dependent. It cannot be fully captured by overall dispositions, but refers to the way we relate to specific others, some of whom are more close to our heart than others, because they are part of the "group self" (Ellemers, 2012). This is the case, not only because of genetic overlap, or because we personally know and like specific individuals within our own community. Behavioral guidelines that may originate from their evolutionary and survival value also extend to people we do not know and will probably never encounter-only because they seem to be related to ourselves at a more abstract and symbolic level (for instance, because we approve of their motives, or because we share the same religious background, or political ideals). These are the people that are special for us because we share the same social identity: a term used to indicate that (p. 153) these individuals embody the conviction of who we are, what we stand for, and where we belong in the world. Considering how other individuals relate to us in terms of our social identity raises social consensus about who is worthy of moral treatment. This also helps us decide whom we might trust to treat us well, and who might best be avoided. Ingroup members who share the same identity seem to deserve more help and fair treatment than outgroup members-regardless of how we test on personality measures indicating overall levels of altruism or empathy.

This distinction in the way we consider individuals based on whether or not they seem to share our social identity, also can explain why a certain act seems morally wrong when perpetrated by one individual while the exact same behavior can be condoned or even approved when displayed by another-merely because of who these individuals are and what they stand for. Stealing is wrong, but Robin Hood is admired because he steals from the rich to help the poor. One should not kill, but we empathize with TV series character Dexter-who routinely kills people because they are serial murderers. To understand hu- 
man morality we have to understand how people consider different circles of care in their moral reasoning. People in Western societies may endorse fairness as a general principle, without thinking about the unfairness in depleting global natural resources or exploiting cheap labor in the third world as relevant to their own sense of morality.

These examples not just confront uncomfortable truths, but are meant to elucidate the point that the essence of human morality cannot be captured by assessing particular traits or characteristics of specific individuals. The morality of one's own actions, as well as judgments about the morality of others do not rely on their possession of specific traits or motivations, but is the result of group identity concerns and relations between different groups in society. Group memberships and common identities do not only determine whom we consider worthy of moral treatment; they also imply that the moral behavior of other members of our group reflects upon the self.

Research has unequivocally established the phenomena of "collective guilt" and "collective shame" (Branscombe \& Doosje, 2004). We emotionally condemn ourselves for acts that were perpetrated by who belong to the same group. We do this even if we can be in no way held accountable for what they did or will never be confronted with their victims, because this all happened at the other end of the world, or before we were born. We experience guilt for war crimes that happened generations ago, or are ashamed of the way our ancestors used slaves for cheap labor. In turn, these symbolic feelings of collective responsibility for the immoral behavior of other ingroup members can motivate individuals to display moral behavior, for instance when present generations engage in reparation efforts to redress or compensate for past injustice.

As a result of the social identities that connect specific groups of individuals in societyor distinguish between them-we differentiate in the moral behavior we extend to others and the moral judgments we reserve for them. Evaluations of the morality of other ingroup members are mainly driven by concerns about the way their behavior reflects upon our own sense of self, as this defines the identity we share with them. Responses to identical information about the (im-)morality of outgroup members mainly raises concerns about our physical safety (p. 154) (Brambilla, Sacchi, Pagliaro, \& Ellemers, 2013). Hardship encountered by fellow nationals who are driven from their homes, for instance because of natural disasters, raises empathy and willingness to help. At the same time migrants from foreign countries who seek refuge from war or poverty can be seen as less worthy of helpful treatment. Business tycoons who are accused of fraud or corruption face moral disapproval, while we justify creative bookkeeping or attempts at tax evasion in our own place of work.

These examples and implications of moral behavior and moral judgment among humans cannot be understood by referring to individual dispositions towards empathy, altruism or fairness. Moral approval depends on more fluid and context dependent behavioral requirements. Instead of being contained in specific behavioral displays, the moral stature of human individuals conveys the more general notion of whether they can be relied on as trustworthy members of the group. Which behavioral requirements they have to meet to 
prove their worthiness, is a matter of social judgment and is jointly defined by important members of the group. Thus, among humans, moral behavior can materialize in many forms and shapes. Yet it is considered key as the most diagnostic feature of human essence in self-views and perceptions of others. Human morality cannot be captured by measuring a fixed trait or general disposition that we do or do not possess, but is seen to stem from the motivated choice to behave in ways that communicate the kind of person we want to be in the eyes of others who are important to us.

\section{The Social Functions of Morality}

Understanding human morality requires that we consider its role in establishing and maintaining people's social identities. The final section of this chapter details different social functions moral judgments can have to define the self in relation to others, to secure belongingness and inclusion, and to regulate the behavior of individuals.

\section{Definition of Self in Relation to Others}

How can judgments of our morality be so important to us, while the behavioral standards that are used to assess this are so vague? Whether or not a specific behavior (e.g., the perpetration of violence against others) is condoned, admired or even required, depends on culturally defined rights and obligations (Rai \& Fiske, 2011). This again underlines the social meaning and relational implications of moral behavior in defining one's social standing vis-a-vis others, and goes beyond conceptions of moral behavior relying on broader altruism or fairness concerns.

Among humans, very broad generic moral guidelines can acquire quite specific interpretations in national, religious, or political groups. These more specific moral guidelines are then used to define the group's distinct identity, making clear how the group differs from other groups. This happens even to the extent that it may no longer be evident to others how the group-specific moral guideline relates to more broadly shared principles. Groups may well endorse the "do no harm" principle as a basic moral guideline, while at the same time prescribing violations of the physical integrity of newborns by circumcision, or putting their members at risk to contagious diseases by refusing vaccination. Because the moral implications of different behaviors are not always self-evident, even individual group members who understand important moral guidelines at a general level, often have to rely on the counsel of a Rabbi, Priest, Imam, or judge to decide whether particular acts are considered morally right or wrong.

(p. 155) Individual moral norms are socially defined. An individual 's sense of right versus wrong is not given at birth nor does it materialize out of the blue during childhood. Instead moral awareness, moral guidelines and moral judgments are acquired through landmark experiences as well as carefully crafted education and socialization practices provided by others around us. This is also the process during which generic social norms can develop into very specific group moral guidelines that are internalized by individuals as part of their "moral compass." In fact, our internal moral compass is developed in con- 
junction with the groups in which we are socialized, turning those groups into our moral anchors. These group-level guidelines can either steer us towards (when the moral standards of the group are more strict than our own) or make us drift away (when they are more lax) from the course of action marked by our own moral compass. In turn, the groups people associate with, and the moral standards that differentiate this group from others, convey important information about the way we ideally think of ourselves and want to be seen by others.

\section{Belongingness and Inclusion}

The essence of group-level moral guidelines thus is that they allow us to attach social meaning to the behavior of ourselves and others. The more distinctive these group morals are, the more suitable they are to communicate who people are and what they stand for. Different moral principles can come to the fore in different groups. In addition to general "do no harm" and fairness principles, people can strive to show loyalty and respect to others in the group, or to guard their physical and spiritual purity (Haidt, 2012). Each of these basic guidelines may seem equally valid as a moral principle. Yet groups that endorse different moral principles can vehemently disagree about what is the "right" way to behave. Additionally, as explained earlier, group-specific interpretations of universal moral guidelines such as "do no harm" can lead to diametrically opposing recommendations, for instance depending on the perspective on acts that cause harm (e.g., as an important learning experience), the targets they address (e.g., ingroup versus outgroup members), or the justifications provided (e.g., avoidance of greater evil).

Adhering to guidelines prescribing what are "right" versus "wrong" behaviors and motivating this by referring to shared values thus can help demonstrate a person's willingness to submit to group-level morals. This can be recognized by others as a mark of identity. It also offers a way to pledge one's loyalty to collectively defined behavioral principles, which is used by other members of the group to test the suitability and determination of those who want to be included. Thus, the definition of specific group morals provides an opportunity for individuals to prove their worthiness as a group member. It allows the group to assess who can be trusted to behave in ways that maintain the group's distinct identity, and offers a valid reason to exclude those who fail to do so.

\section{Behavioral Regulation}

For all the reasons cited earlier, (not) adhering to group morals can have severe social implications. Accordingly, there is clear empirical evidence demonstrating that the desire to be moral is a very powerful behavioral motive. Experimental designs have allowed us to establish that emphasizing the moral implications of one's behavior makes people try harder to act in line with moral guidelines, and causes more stress when they fail to do so. This is evident at a very basic psychophysiological level, for (p. 156) instance in characteristic and unique patterns of cardiovascular and brain activity. These indicate enhanced mobilization of cognitive and energetic resources to perform well in the moral domain, and greater impact of feedback about their success versus failure in achieving this. For 
instance, compared to tasks that allow them to demonstrate their competence, people are more attentive to information when they think this is relevant to their moral behavior, they invest more energy in displaying such behavior, and experience more stress when their performance is said to be substandard.

The group-level nature of moral motivations is evident from the fact that the impact of moral guidelines differs depending on whether these are provided by ingroup or outgroup members. That is, whereas people adapt the choices they make in order to behave in line with what the ingroup considers moral, they adhere to their individual behavioral preferences when the same moral guidelines are provided by members of another group. Likewise, when their behavior is monitored by an ingroup member, people show enhanced attention to information that is relevant to the task, as they try to control their moral performance. No such evidence of enhanced attention or task motivation is found when their moral performance is monitored by an outgroup member, suggesting that people care less about being considered moral by those who belong to a different group (Ellemers \& Van der Toorn, 2015).

The experimental designs in which this is established resonate with real life observations, while making clear that the added value of moral group norms and moral behavior is located primarily at the symbolic level. That is, these effects occur even with relatively meaningless experimental tasks, ambiguous behaviors, counter-intuitive moral guidelines, and experimentally created group memberships. This also elucidates that the real life implications of moral group norms often are stronger, as behaviors are more consequential, there is more time to internalize social norms, and group memberships acquire more meaning. As a result, group-specific guidelines can cause individuals to behave in ways they see as morally acceptable, and cause them to defend these morals even when they are criticized by members of other groups for behaving immorally. This reasoning also explains the occurrence and persistence of organizational behaviors that are considered morally objectionable by the general public (Treviño, Den Nieuwenboer, \& KishGephart, 2014).

\section{The Challenge of Human Morality: Who De- fines What Is Morally Right?}

With reference to universal morals, people tend to assume there is general agreement about what is moral and not moral, and that those who act in ways be consider immoral only need to be reminded of what is morally good. However, we have to consider that the same abstract principles can be seen to give rise to very different behavioral guidelines, and that different groups in society may have good reason to develop and defend their distinct and unique set of group morals. As a result, different groups in society can each have their own sense of morality, be convinced that they are acting out of the desire to be morally good, and reject other interpretations of broader moral principles. Indeed, these moral value clashes between different groups in society explain why it may be extremely 
difficult to come to terms with existing differences in the way people behave, or seem impossible to resolve conflicting morals (Skitka \& Mullen, 2003).

This is the challenge offered by morality in larger and more complex human (p. 157) societies, where members of different ethnic groups, and endorsing different political or religious convictions have to work and live together. The combination of different skills, abilities and gene pools offered in this way potentially benefits human development and survival. However, this comes with the cost of seemingly insurmountable moral value differences, and incompatible behavioral guidelines that are an ongoing source of tension and intergroup conflict.

The analysis in terms of distinct group morals and the social functions they serve makes clear that the main challenge of human morality is not entailed in people lacking empathy, nor can it be resolved by simply educating them about the implications of their actions for the outcomes of others. Instead, the main challenge is to find a way to interact with others who endorse conflicting or incompatible moral values, while each party strongly believes in its own moral righteousness and superior moral values. Elaborate communications, sophisticated language use, strategic choice of descriptive terms and explanations and leadership rhetoric are an important part of this process, and make the symbolic nature of moral judgments a unique aspect of human essence.

\section{Conclusion}

Human morality provides a system of moral guidelines and judgments that is used to help regulate social interactions in larger and more complex societies. These are characterized by the presence of multiple groups, which can mainly have symbolic value instead of being defined by mutual interdependence, direct contact, or genetic similarity. In such contexts, the communicative, symbolic, and political functions of moral prescriptions are key, as shared moral guidelines offer an effective and efficient mechanism for top-down regulation of individual behavior. Unlike what we consider "moral" behavior in other animals, the moral implications of human behavior are not always directly visible from overt displays of empathy or helping. Instead, these often have to be inferred from the perceived motives underlying more ambiguous actions that are visible to others. Sometimes quite complex narratives are used to explain the moral guidelines underlying behaviors that are not obviously moral (for instance when sacrificing some to save others). Sometimes very peculiar and specific behaviors are displayed to demonstrate knowledge of specific moral norms and mark affiliation with a particular group and its unique features.

Among humans, moral guidelines and judgments are used to regulate and contain the behavior of individuals, but also to distinguish between different groups and communities. Moral rules help to select targets that are (not) worthy of helping, which are not necessarily defined by kinship ties or direct social interdependence relations. This unique feature of human morality raises additional and more complex questions, the resolution of which does not necessarily benefit from a comparison with animal "morality." Thus, the essence of human morality is that we can and do endorse different moral value systems

Page 12 of 14

PRINTED FROM OXFORD HANDBOOKS ONLINE (www.oxfordhandbooks.com). (c) Oxford University Press, 2018. All Rights Reserved. Under the terms of the licence agreement, an individual user may print out a PDF of a single chapter of a title in Oxford Handbooks Online for personal use (for details see Privacy Policy and Legal Notice). 
as a way to regulate behavior of individuals in particular social contexts. Notwithstanding the social benefits of these systems, the dynamics involved also provide a pervasive source of conflicts between groups and offer cause for dehumanization of others who adhere to different moral standards. The moral values that make us human also tempt us to view ourselves and our groups as morally superior, and make others seem less worthy of moral treatment simply because they endorse a different moral value system. (p. 158) This is the unique paradox of human morality.

\section{Further Reading}

Ellemers, N., \& Van der Toorn, J. (2015). Groups as moral anchors. Current Opinion in Behavioral Sciences, 6, 189-194.

Haidt, J. D. (2012). The righteous mind: Why good people are divided by politics and religion. New York. NY: Random House.

Treviño, L. K., Den Nieuwenboer, N. A., \& Kish-Gephart, J. J. (2014). (Un)ethical behavior in organizations. Annual Review of Psychology, 65, 635-660.

\section{References}

Brambilla, M., Sacchi, S., Pagliaro, S., \& Ellemers, N. (2013). Morality and intergroup relations: Threats to safety and group image predict the desire to interact with outgroup and ingroup members. Journal of Experimental Social Psychology, 19, 811-821.

Branscombe, N. R., \& Doosje, B. J. (2004). (Eds.) Collective guilt: International perspectives. Cambridge, England: Cambridge University Press.

De Waal, F. (1996). Good natured: The origins of right and wrong in humans and other animals. Cambridge, MA: Harvard University Press.

Ellemers, N. (2012). The group self. Science, 336, 848-852.

Ellemers, N., Pagliaro, S., \& Barreto, M. (2013). Morality and behavioural regulation in groups: A social identity approach. European Review of Social Psychology, 24, 160-193.

Ellemers, N., \& Van der Toorn, J. (2015). Groups as moral anchors. Current Opinion in Behavioral Sciences, 6, 189-194.

Fiske, A. P., \& Rai, T. S. (2014). Virtuous violence: Hurting and killing to create, sustain, end, and honor social relationships. Cambridge, England: Cambridge University Press.

Giner-Sorolla, R. (2012). Judging passions: Moral emotion in persons and groups. Hove, England: Psychology Press.

Haidt, J. D. (2012). The righteous mind: Why good people are divided by politics and religion. New York, NY: Random House. 
Haidt, J., \& Kesebir, S. (2010). Morality. In S. Fiske, D. Gilbert, \& G. Lindzey (Eds.), Handbook of social psychology. (5th ed., pp. 797-823). Hoboken, NJ: Wiley.

Haslam, N., \& Loughnan, S. (2014). Dehumanization and infrahumanization. Annual Review of Psychology, 65, 399-423.

Janik,V. M. (2013). Cognitive skills in bottlenose dolphin communication. Trends in Cognitive Science, 17, 157-159.

Rai, T. S. \& Fiske, A. P. (2011). Moral psychology is relationship regulation: Moral motives for unity, hierarchy, equality, and proportionality. Psychological Review, 118, 57-75.

Shalvi, S., Gino, F., Barkan, R., \& Ayal, S. (2015). Self-serving justifications: Doing wrong and feeling moral. Current Directions in Psychological Science, 24, 125-130.

Skitka, L. J., \& Mullen, E. (2003). The dark side of moral conviction. Analysis of Social Issues and Public Policy, 2, 35-41.

Tangney, J. P., \& Dearing, R. L. (2002). Shame and guilt. New York, NY: Guilford.

Tomasello, M., \& Vaish, A. (2013). Origins of human cooperation and morality. Annual Review of Psychology, 64, 231-255.

Treviño, L. K., Den Nieuwenboer, N. A., \& Kish-Gephart, J. J. (2014). (Un)ethical behavior in organizations. Annual Review of Psychology, 65, 635-666.

\section{Naomi Ellemers}

Naomi Ellemers Department of Social, Health, and Organizational Psychology Utrecht University Utrecht, the Netherlands 